\title{
Effects of photodynamic therapy on Enterococcus faecalis biofilms
}

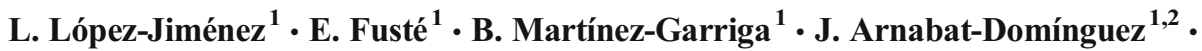 \\ T. Vinuesa ${ }^{1} \cdot$ M. Viñas ${ }^{1}$
}

Received: 3 July 2014 / Accepted: 20 March 2015 /Published online: 28 April 2015

(C) The Author(s) 2015. This article is published with open access at Springerlink.com

\begin{abstract}
Microbial biofilms are involved in almost all infectious pathologies of the oral cavity. This has led to the search for novel therapies specifically aimed at biofilm elimination. In this study, we used atomic force microscopy (AFM) to visualize injuries and to determine surface roughness, as well as confocal laser scanning microscopy (CLSM) to enumerate live and dead bacterial cells, to determine the effects of photodynamic therapy (PDT) on Enterococcus faecalis biofilms. The AFM images showed that PDT consisting of methylene blue and a 670 -nm diode laser (output power $280 \mathrm{~mW}$ during $30 \mathrm{~s}$ ) or toluidine blue and a 628-nm LED light (output power $1000 \mathrm{~mW}$ during $30 \mathrm{~s}$ ) induced severe damage, including cell lysis, to E. faecalis biofilms, with the former also causing an important increase in surface roughness. These observations were confirmed by the increase in dead cells determined using CLSM. Our results highlight the potential of PDT as a promising method to achieve successful oral disinfection.
\end{abstract}

Keywords Atomic force microscopy $\cdot$ Confocal laser scanning microscopy $\cdot$ Photodynamic therapy $\cdot$ Enterococcus faecalis $\cdot$ Surface roughness

M. Viñas

mvinyas@ub.edu

1 Laboratory of Molecular Microbiology and Antimicrobials, Department of Pathology and Experimental Therapeutics, Medical School, IDIBELL-University of Barcelona, Barcelona, Spain

2 Department of Dentistry, Dentistry School, IDIBELL-University of Barcelona, Barcelona, Spain

\section{Introduction}

A microbial biofilm is a three-dimensional, complex structure attached to a surface or interface and comprising microorganisms embedded in an extracellular polymeric matrix [1]. Although laboratory studies of biofilm formation and structure commonly make use of monospecies biofilms, in nature, biofilms are frequently formed by more than one species and in some cases by hundreds of species. An excellent example is oral biofilms, referred to as dental plaques [3, 4]. These typically contain an enormous variety of bacterial species, many of which are responsible for infections in the oral cavity and even elsewhere in the body [2]. Dental caries, periodontal diseases, endodontic infections, and numerous pathologies beyond the oral cavity have been attributed to the proliferation of oral bacteria and their ability to form and participate in stable polymicrobial biofilms.

Microbes living in a biofilm are subjected to environmental conditions that promote behaviors clearly different from those of planktonic forms. Transcriptomic studies have identified several genes that are overexpressed in sessile vs. planktonic bacteria, whereas other genes are downregulated [5]. In addition, bacteria in biofilms are typically much more resistant to antimicrobials than their planktonic counterparts [6], although the latter are used in the clinical testing of susceptibility.

Oral bacteria grow exclusively (or almost) in biofilms. Thus, the main goal of oral disinfection is biofilm destruction, together with elimination of the remaining viable bacteria. Because of its anatomical complexity, the root canal system acts as a reservoir of several bacterial species that grow in biofilms. Mechanical disruption and antimicrobial therapies are currently the most frequently used methods to treat and eliminate oral biofilms; however, the effectiveness of these strategies is limited by the emergence of resistant microorganisms and the common persistence of a small proportion of 
viable bacteria, both of which can largely if not completely regenerate the community [7]. Consequently, there has been extensive research into the development of alternative therapeutic methods, such as laser light treatments and photodynamic therapy (PDT) $[8,9]$. In the former, high-power lasers are used together with an intracanal optical fiber first to kill the microorganisms by means of a photothermal effect and then to disinfect areas unreachable by traditional endodontic treatments [10-12]. However, high-power lasers may cause thermal injuries to dental tissues, such as dentin carbonization and cratering, root resorption, cementum melting, and periradicular necrosis [13-15]. Thus, PDT, in which low-power lasers drive photochemical reactions, has been suggested as a promising approach to fight oral infections without the undesirable effects associated with temperature increases. PDT is based on the use of photosensitizers, molecules that are activated by light in the presence of air. Activation leads to the generation of highly reactive singlet oxygen and free radicals that have cytotoxic effects on living cells [2]. Singlet oxygen is a diamagnetic form of oxygen and is responsible for the damaging effects of sunlight on organic materials. It is usually produced by means of photosensitizer pigments (most of them vital stains) and is stable for over an hour at room temperature. PDT has been used to kill cancer cells and bacteria, by exploiting their sensitivity to singlet oxygen. In principle, photosensitizers can penetrate both gram-positive and gram-negative bacteria, without affecting host cell viability [16]. Moreover, bacteria are unlikely to develop resistance to repeated photosensitization [17]. Several studies have reported the successful use of PDT in reducing bacterial counts in the root canal system, recommending it as an adjunctive antimicrobial procedure in conventional endodontic treatment [18-22]. It has been pointed out that PDT is as effective as conventional $5 \% \mathrm{NaOCl}$ irrigation against Enterococcus faecalis [23]. Moreover, the efficacy of PDT on biofilms seems to be strain dependent [24].

In this study, we examined the effects of PDT on biofilms of Enterococcus faecalis, a gram-positive bacterium resistant to some antibiotics and frequently found in the oral cavity of patients who have undergone root canal treatment. Our combined approach consisted of atomic force microscopy (AFM), confocal laser scanning microscopy (CLSM), and surface roughness determinations. The results highlight the potential of PDT to achieve successful oral disinfection.

\section{Material and methods}

\section{Bacterial strain, culture conditions, and biofilm formation}

E. faecalis, American Type Culture Collection (ATCC) 29212, was grown overnight in $20 \mathrm{ml}$ of trypticase soy broth (Scharlau, Barcelona, Spain) at $37^{\circ} \mathrm{C}$ with orbital shaking at $250 \mathrm{rpm}$. The culture was used to inoculate 24-well culture plates containing $2 \mathrm{ml}$ of growth medium to yield a bacterial concentration of $10^{6}$ colony-forming units $(\mathrm{cfu}) / \mathrm{ml}$. Each well contained a Thermanox coverslip previously coated with a $0.01 \%(w / v)$ poly-L-lysine hydrobromide (Sigma-Aldrich, Dorset, UK) solution to enhance bacterial cell adhesion and to prevent biofilm removal during the experiments. The plates were incubated at $37{ }^{\circ} \mathrm{C}$ for $24 \mathrm{~h}$ under gentle shaking (60 rpm) to allow biofilm formation.

\section{Photosensitizers and light sources}

The photosensitizers tested in this study consisted of two dyes, toluidine blue $\mathrm{O}(\mathrm{TBO})$, at $0.1 \mathrm{mg} / \mathrm{ml}$, and 3,7 bis(dimethylamino)-phenazathionium chloride trihydrate (methylene blue, MB), at $0.005 \%(w / v)$ in phosphatebuffered saline containing hydroxymethylcellulose as a mucoadhesive viscosity agent (Periowave, Ondine Biopharma, Vancouver, BC, Canada). Both TBO and MB are commonly used in oral antimicrobial PDT. Their activities as potent photosensitizers against gram-negative and grampositive bacteria were previously documented [2].

A light-emitting diode (LED) lamp (FotoSan; CMS Dental, Copenhagen, Denmark), emitting in the red spectrum with a peak at $628 \mathrm{~nm}(620-640 \mathrm{~nm})$, was used as the light source together with TBO. The LED lamp has an output power of $1000 \mathrm{~mW}$ for $30 \mathrm{~s}$, total energy delivered was $30 \mathrm{~J}$; surface at the end of the fiber was $6 \mathrm{~mm}$ diameter, and an energy density of $106.4 \mathrm{~J} \mathrm{~cm}^{-2}$. For MB, diode laser light (Periowave; Ondine Biopharma, Vancouver, Canada) emitting at a wavelength of $670 \mathrm{~nm}$ served as the light source. It has an output power of $280 \mathrm{~mW}$ during $30 \mathrm{~s}$, total energy delivered was $8.4 \mathrm{~J}$, and an energy density of $271 \mathrm{~J} \mathrm{~cm}^{-2}$.

\section{PDT}

The biofilms were gently washed with distilled water to remove nonadherent bacteria. The experimental conditions were (i) biofilms sensitized with TBO in darkness for $1 \mathrm{~min}$, (ii) biofilms sensitized with TBO in darkness for $1 \mathrm{~min}$ and then treated with LED for $30 \mathrm{~s}$, (iii) biofilms sensitized with MB in darkness for $1 \mathrm{~min}$, and (iv) biofilms sensitized with $\mathrm{MB}$ in darkness for $1 \mathrm{~min}$ and then exposed to diode laser for $30 \mathrm{~s}$. The controls consisted of (i) biofilms treated neither with photosensitizers nor with light sources, (ii) biofilms treated only with the diode laser for $30 \mathrm{~s}$, and (iii) biofilms treated only with the LED lamp for $30 \mathrm{~s}$. After treatment, all of the biofilms were gently washed with distilled water and visualized by AFM and CLSM.

\section{AFM imaging}

Samples were imaged in air using an atomic force microscope XE-70 (Park Systems, Korea). All images were collected in 
noncontact mode using pyramidal-shaped silicon cantilevers with a spring constant of $\pm 40 \mathrm{~N} \mathrm{~m}^{-1}$, a resonance frequency of $\pm 300 \mathrm{kHz}$, and their upper sides coated with aluminum to enhance the reflectivity of the laser beam. AFM images were simultaneously acquired with several scan sizes (100, 25, and $6.25{\mu \mathrm{m}^{2}}^{2}$ at a scan rate of $0.3-0.5 \mathrm{~Hz}$. Data acquired during surface scanning were converted into images of topography, amplitude, and phase and then analyzed using XEP and XEI software (Park Systems, Korea). Topography images reveal the shape and structure of the sample as well as surface differences. Amplitude images highlight the sample outline and allow visualization of fine surface details. Phase images show variations in the elasticity and viscoelasticity of the sample.

\section{CLSM imaging}

Biofilms on the Thermanox coverslips were washed three times with distilled water to remove loose bacteria and then stained using the LIVE/DEAD BacLight bacterial viability kit (Molecular Probes, Eugene, OR). In this system, live bacteria stain with Syto 9 to produce a green fluorescence whereas bacteria with compromised membranes stain with propidium iodide to produce a red fluorescence. Images of the doublestained biofilms were acquired using a Leica TCS-SL filterfree spectral confocal laser scanning microscope (Leica Microsystems, Mannheim, Germany) equipped with a 488$\mathrm{nm}$ argon laser and 543- and 633-nm He/Ne lasers (Centres Científics i Tecnològics, Universitat de Barcelona, Barcelona, Spain) and $\mathrm{a} \times 63$ oil immersion objective (1.4 numerical aperture) zoom 1 , where the $x, y$, and $z$ voxel size corresponded to $0.23 \times 0.23 \times 0.4 \mu \mathrm{m}$ with an image resolution of $1024 \times$ 1024 pixels. The pinhole size was kept at the minimum setting (1.0-1.08 AU). Image saturation was prevented by lowering the gain and offset in the brightest signal. Sequential scanning was carried out for each channel. CLSM images were analyzed by using ImageJ software (National Institutes of health, Bethesda, MD, USA). A threshold selection method was created to distinguish between one and two bacteria. Alive and dead bacteria percentages were calculated from the total number of bacteria. Values (percentages) were arcsine transformed. Furthermore, data were analyzed by KolmogorovSmirnov test and Levene one-way ANOVA tests. $P$ values lower than 0.05 were considered as statistically significant.

\section{Surface roughness}

AFM was also used to measure the surface roughness of the treated and untreated biofilms. The roughness average $\left(R_{a}\right)$, defined as the average distance from the roughness profile to the center plane of the profile, was calculated from the acquired topography images for every scan size and treatment.

\section{Bacterial enumeration}

The CLSM images were analyzed using ImageJ (National Institutes of Health, Bethesda, MD, USA) to enumerate viable and dead bacteria, differentially stained as described above. A thresholding procedure was established for every image, and a watershed separation was applied to separate clusters of bacteria. Percentages of live and dead bacteria in every treatment were determined.

\section{Results}

\section{Visualization of PDT effectiveness}

Representative AFM images of treated E. faecalis biofilms are shown in Fig. 1. An analysis of the AFM topography 3Dimages showed that PDT induced severe morphological and surface alterations of the biofilms as well as a broad spectrum of injuries to the resident bacterial cells, whereas in the untreated biofilms, E. faecalis retained its typical coccoid shape (Fig. 1a). In the biofilms treated with TBO (1 min) plus LED (30 s), bacterial wall destruction, loss of the typical cell morphology, and leakage of the intracellular contents were observed (Fig. 1f). The injuries to biofilms treated with MB (1 min) plus diode laser (30 s) were similar (Fig. $1 \mathrm{~g})$ but much more apparent. Neither TBO nor MB alone was able to induce noticeable morphological alterations (Fig. 1d, e), as only a small proportion of bacterial cells were even slightly affected. Conversely, light therapy in the absence of the dyes caused slight changes in biofilm topography (Fig. 1b, c).

\section{Surface roughness}

Changes in the surface roughness of treated vs. untreated biofilms can be numerically expressed using the XEI software and processing the topography images previously obtained at scan sizes of 25 and $6.25 \mu^{2}$. Figure 2 shows the mean surface roughness values $\left(R_{a}\right)$ of control and treated $E$. faecalis biofilms. PDT-treated biofilms had high surface roughness values. By contrast, the roughness values measured after treatment of the biofilms with the dyes or with either light source alone were not significantly modified.

\section{CLSM}

Enumeration of the viable and dead bacteria for every treatment showed a significant increase in bacterial death in E. faecalis biofilms treated with PDT. Neither of the photosensitizers alone resulted in significant bacterial killing, as the proportion of living bacteria in either case was almost identical to that in the negative controls (about $2 \%$ ). LED treatment in the absence of photosensitizer had a slight lethal effect, with 
a)

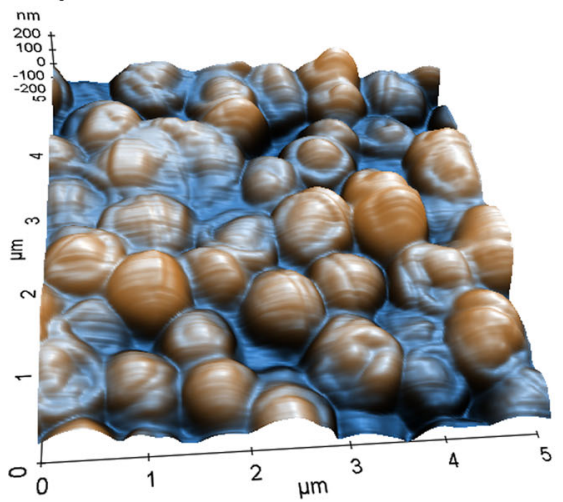

d)

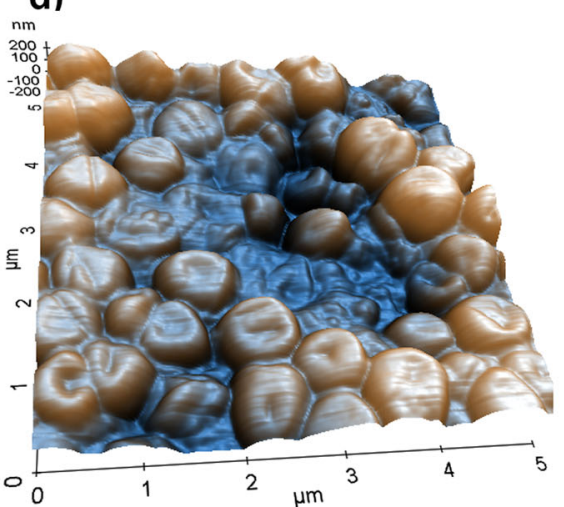

f)

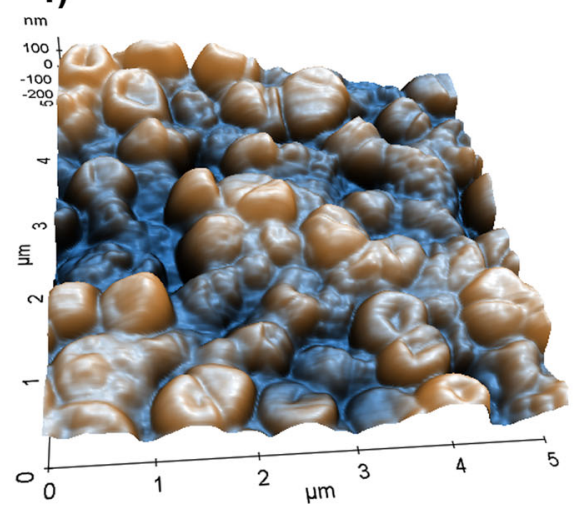

Fig. 1 AFM 3D topography images of E. faecalis biofilms: untreated (a), exposed to LED for $30 \mathrm{~s}(\mathbf{b})$, exposed to diode laser for $30 \mathrm{~s}$ (c), sensitized 1 min with TBO (d), sensitized 1 min with $\mathrm{MB}(\mathbf{e})$, sensitized 1 min with

approximately $24.2 \%$ of the individual cells exhibiting red fluorescence. Diode laser treatment alone, at least at the power tested, was unable to kill bacteria. On the contrary, PDT caused significant bacterial injury, with more than $95 \%$ lethality in the case of diode laser plus MB and $79 \%$ in the case of LED plus TBO (Fig. 3).

The results of CLSM showed predominance of red fluorescence indicating damaged biofilm cells following PDT treatments in comparison with the control showing green color dominance in biofilm. Representative CLSM images of c)

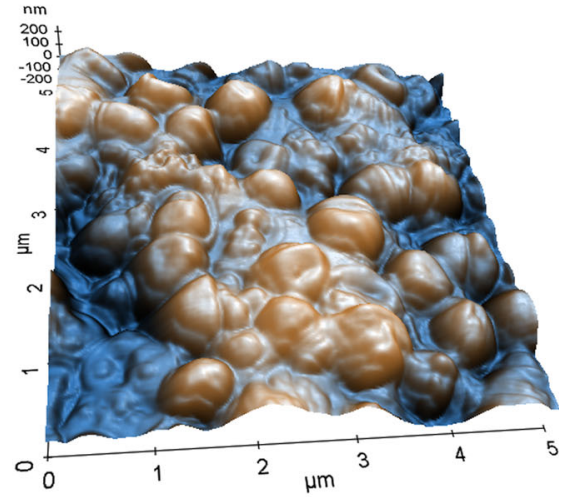

e)

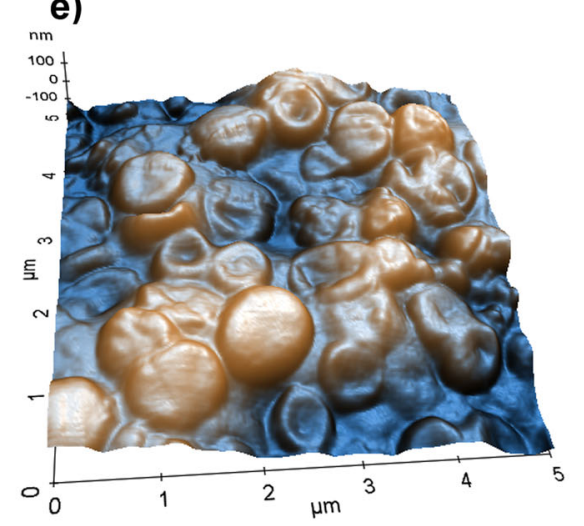

g)

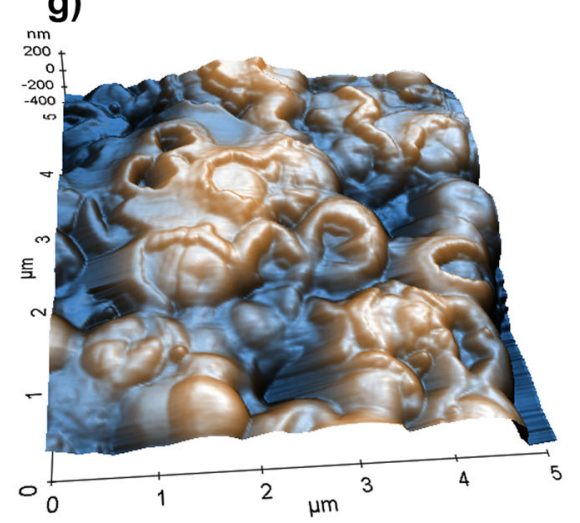

TBO and exposed to LED for $30 \mathrm{~s}$ (f), and sensitized $1 \mathrm{~min}$ with MB and exposed to diode laser for $30 \mathrm{~s}(\mathbf{g})$. Scan size $=25 \mu \mathrm{m}^{2}$

untreated and PDT-treated biofilms are shown in Fig. 4. On the double-fluorescence images of living plus dead bacteria, the majority of the cells in the untreated biofilms stained green (Fig. 4a), indicating a high level of bacterial viability. In biofilms treated with LED plus TBO (Fig. $4 \mathrm{~b}$ ) or diode laser plus MB (Fig. 4c), most of the bacteria stained red, indicating significant bacterial killing. In these PDT-treated images, orange-staining bacteria were considered to be damaged cells. Table 1 shows statistical analysis of the results of CLSM experiments. 


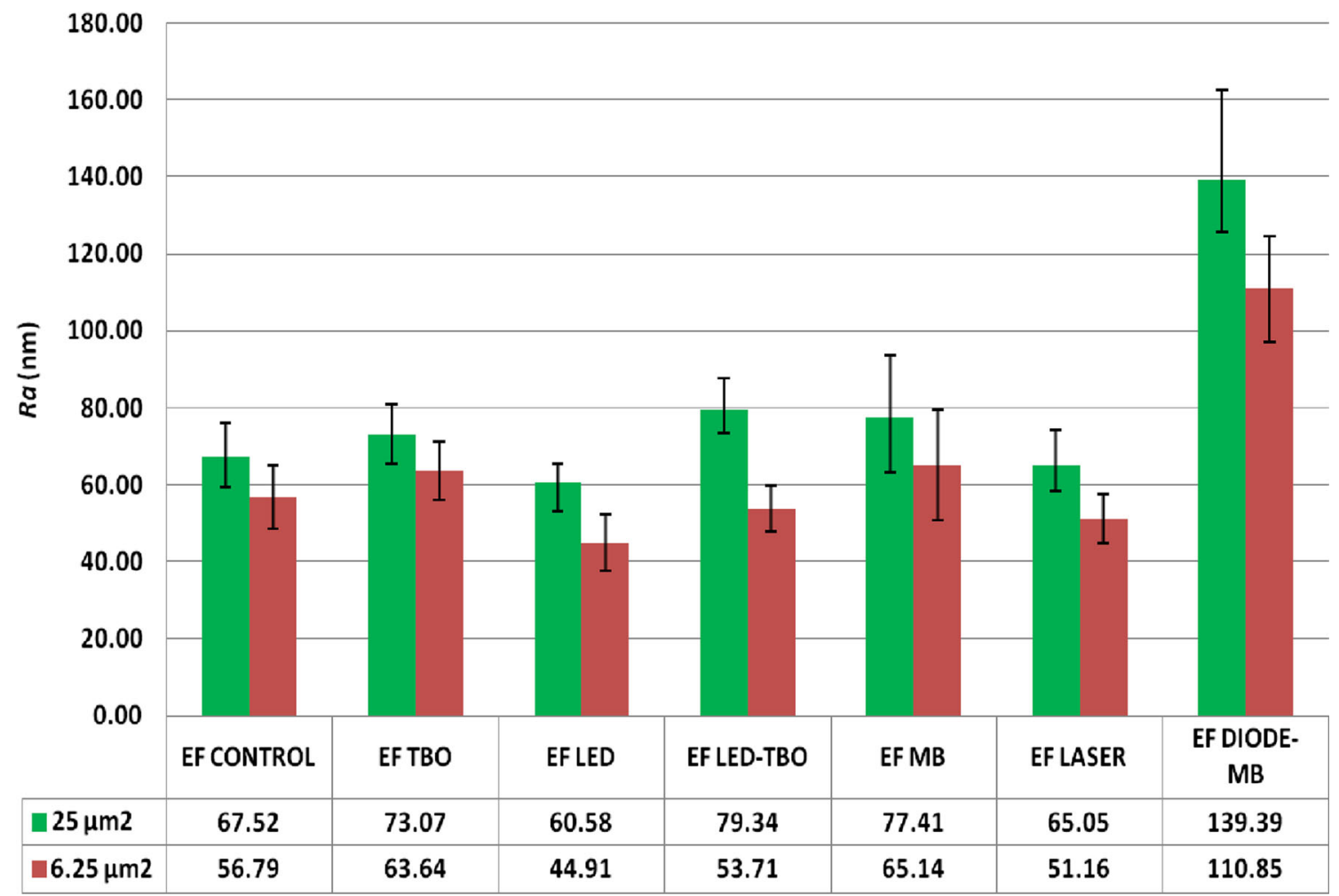

Fig. 2 Graphical representation of surface roughness $\left(R_{\mathrm{a}}\right)$ in nanometers, according to the different treatments tested and surface scan sizes. Bars represent the standard error of the mean. The mean surface roughness values are shown in the table below

\section{Discussion}

In the biofilm mode of growth, microorganisms firmly attached to a surface or interface are enclosed in an extracellular polymeric matrix formed by polysaccharides, nucleic acids, proteins, water, and cell debris. This matrix offers protection against host defenses and often restricts the penetration of antimicrobial agents $[1,25]$. Thus, for infections of the oral cavity, in which the causative agents typically reside in biofilms, conventional treatments are often ineffective. A therapeutic approach is therefore needed that focuses on biofilm removal, the eradication of persistent cells, and the decontamination of oral surfaces. PDT has been used to eliminate bacterial as well as cancer cells. Recently, it has emerged as an
Fig. 3 Graphical representation of living and dead bacteria, according to the different treatments tested. Bars represent the standard error of the mean

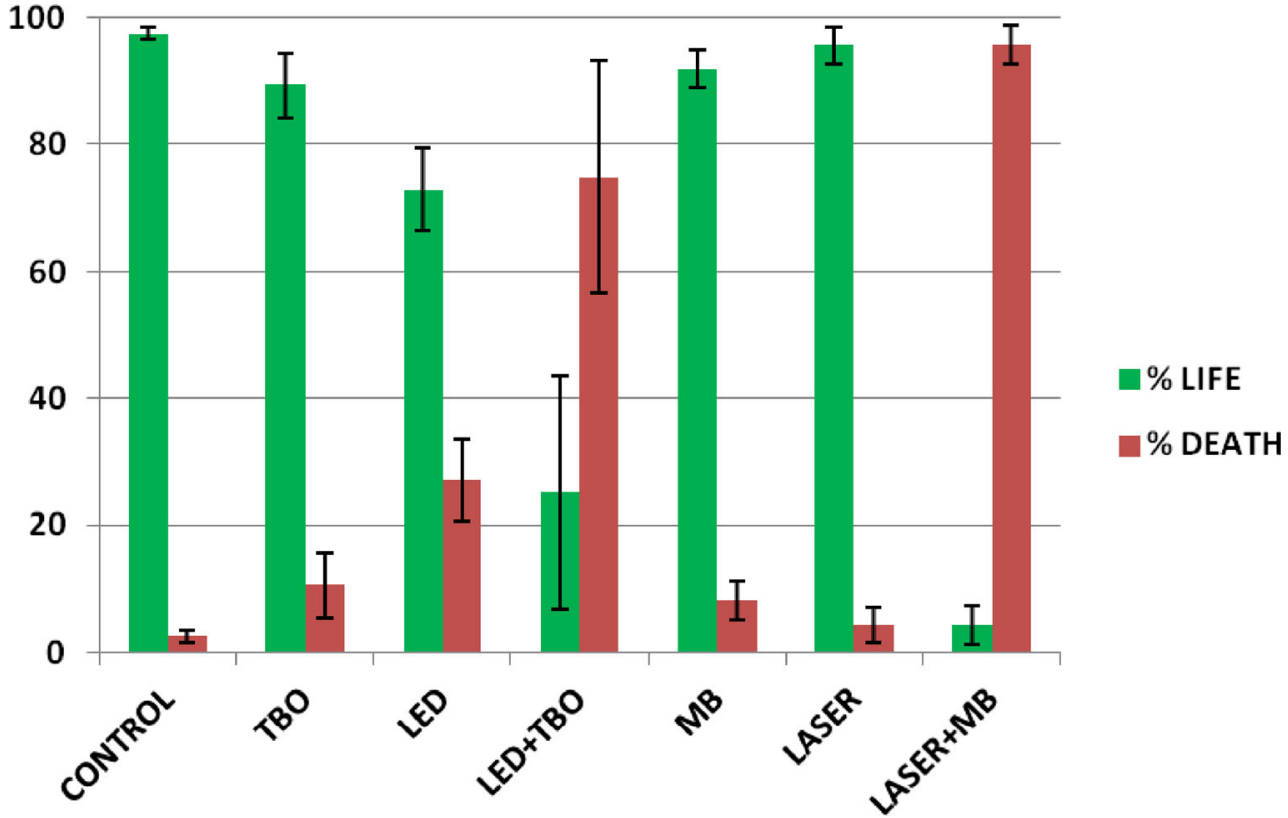


Table 1 Multiple comparisons of percentages of alive/dead bacteria after treatments

\begin{tabular}{lllllll}
\hline & Control & TBO & MB & LED & LASER & LED+TBO \\
\hline TBO & 0.802 & & & & & \\
MB & 0.916 & 0.999 & & & & \\
LED & 0.068 & 0.534 & 0.385 & & & \\
LASER & 0.999 & 0.864 & 0.953 & 0.086 & & \\
LED+TBO & 0.000 & 0.002 & 0.002 & 0.0048 & 0.000 & \\
LASER+MB & 0.000 & 0.000 & 0.000 & 0.010 & 0.000 & 0.973 \\
\hline
\end{tabular}

Statistically significant values are in italics

alternative in the removal of oral biofilms and thus in the prevention or amelioration of infections of the oral cavity.

In the present work, we used three different approaches, AFM, CLSM, and surface roughness determination, to study the efficacy of PDT in the elimination of E. faecalis biofilms formed on Thermanox coverslips. E. faecalis is commonly found in the root canal system of the teeth, where its biofilm-type growth has been documented.

AFM is a powerful tool that, with easy sample preparation, provides high-resolution imaging of microbiological systems [26], individual microbial cells [27], and microbial biofilms [28]. It has also been used to study the mechanical and adhesive properties of microbial cells [26], to assess surface properties such as roughness, both in air and in liquid [29], to evaluate morphological effects of treatments, including those targeting microorganisms [30], and to study microbial cell processes and interactions [31]. However, a limitation of AFM is that under physiological conditions, some structures and morphological features, such as flagella or biofilm matrix components, are poorly visualized by liquid imaging [27, 32-34] because of deficient adhesion of the microbial cells to the substrate. This, in turn, generates sufficient noise during scanning such that image quality is compromised $[35,36]$. In our study, we used air-dried samples since AFM imaging of dried microbial preparations is well established [33, 37]. The advantages include easy sample preparation and highresolution imaging of microbial cell surfaces $[38,39]$. AFM visualizations in air are commonly used to evaluate morphological changes in treated vs. nontreated microbial surfaces [34, 39-44]. Thus, it was the method of choice in the analysis of our air-dried treated and untreated biofilms. Imaging of the latter revealed their normal morphology and low nanoroughness values throughout the incubation period. This result confirmed that the significant morphological alterations and surface injuries observed in the treated samples were produced by PDT and were not sample processing artifacts. Specifically, AFM of the sensitized biofilms revealed that with TBO or MB
Fig. 4 CLSM images of E. faecalis biofilms: untreated (a), treated with LED plus TBO (b), and treated with diode laser plus MB (c). Viable (green) bacteria (left), dead (red) bacteria (middle), and viable and dead bacteria (right). Scale bar $=10 \mu \mathrm{m}$
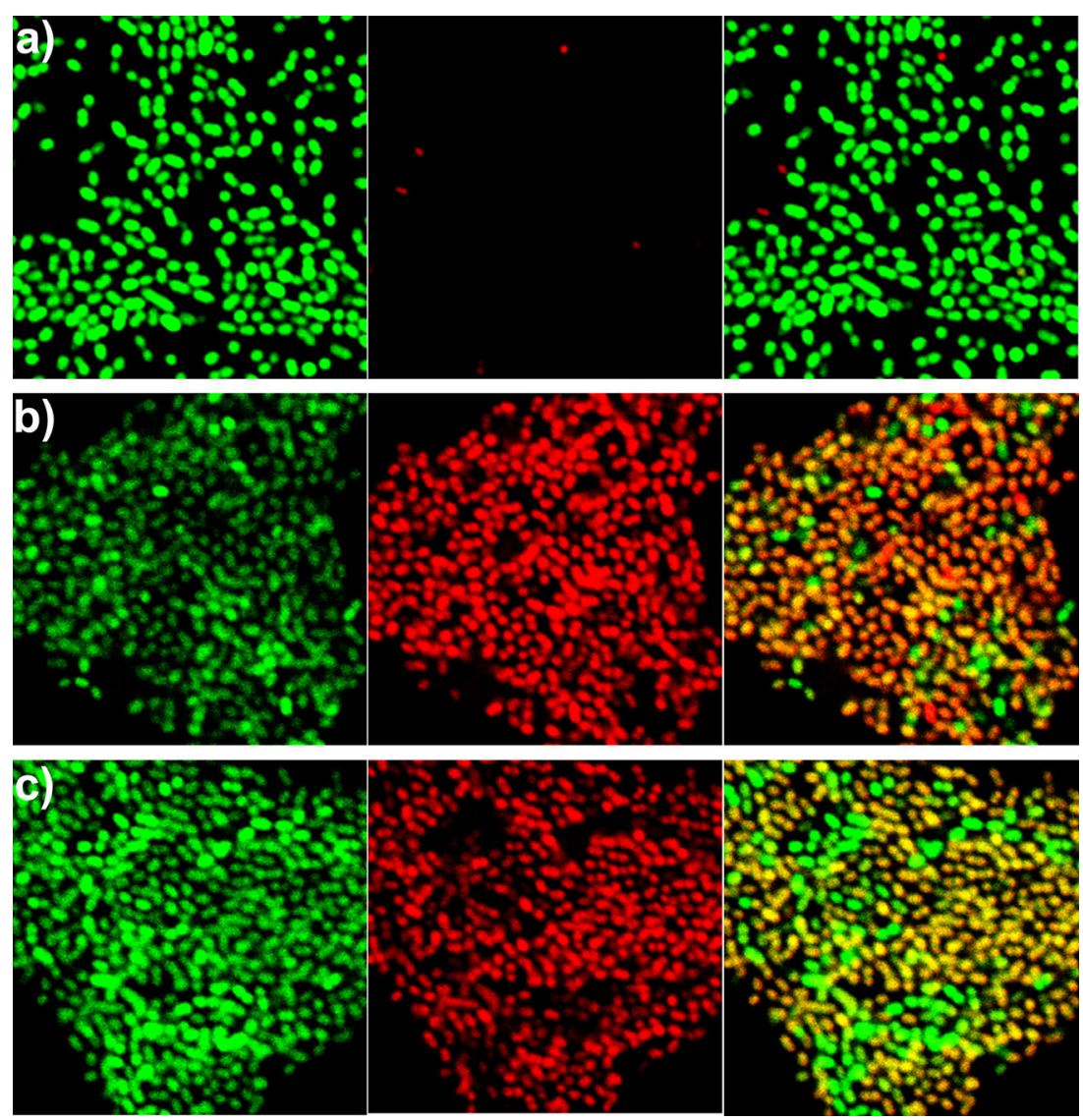
alone only, a small proportion of bacterial cells showed bacterial wall perturbations (Fig. 1d, e). Similar alterations were produced after treatment by light in the absence of dyes (Fig. 1b, c). However, E. faecalis biofilms exposed to PDT (Fig. 1f, g), and particularly those treated with MB and diode laser, showed severe alterations.

A relevant parameter to characterize surface morphology is the determination of surface roughness, expressed as the arithmetic average roughness $R_{a}$ [45]. An increase in cell surface roughness is indicative of a distorted cell morphology, bacterial wall destruction, and leakage of cellular contents, all of which were observed in the PDT-treated biofilms, thus confirming the AFM findings. The surface roughness data also showed that the greatest damage occurred in biofilms exposed to MB and diode laser (Fig. 2). In irradiated cells, photosensitizers may cause alterations to membrane integrity and thus also damage cytoplasmic components [46]. These results support the use of PDT to destroy E. faecalis biofilms.

CLSM was used to assess bacterial viability in biofilms subjected to PDT or to the photosensitizers or light alone and it confirmed our AFM results. With the double-staining method, we were able to distinguish between bacteria with intact (green) and damaged (red/orange) membranes [24]. CLSM images of the untreated biofilm showed that most of the bacteria stained green, indicating their viability (Fig. 4a), whereas the large proportion of red-staining bacteria in the PDT-treated biofilms confirmed the efficacy of this form of treatment (Fig. 4b, c).

Similar results were obtained in previous studies in which the PDT-induced damage to microbial surfaces was assessed. Sahu et al. (2009) [41] used AFM to visualize the topographical alterations produced by TBO-mediated PDT in Staphylococcus aureus and Escherichia coli. They observed perturbations to the bacterial wall, bleb formations suggestive of damage to membrane components, and an increase in cell surface roughness. Cheng et al. (2012) [8] evaluated the bactericidal effect of several different laser irradiation methods and PDTs in root canals experimentally infected with $E$. faecalis, using scanning electron microscopy (SEM) to examine the morphology of bacterial cells before and after treatment. SEM revealed the shrunken, rough, and fractured appearance of the bacterial cells that remained after PDT. Melo et al. (2013) [47] used AFM to examine the PDT-induced changes in the shape and size of Streptococcus mutans cells. The combination of TBO and LED resulted in a decrease in the diameter of the bacterial cells. Garcez et al. (2013) [48] also demonstrated the effect of PDT to disrupt Pseudomonas aeruginosa and E. faecalis biofilms in prepared root canals. SEM analysis showed a significant reduction of biofilm after treatment with $\mathrm{MB}$ and a diode laser.

The severe perturbations of $E$. faecalis biofilms produced by PDT recommend its use in the eradication of bacterial biofilms. Nevertheless, further studies that include supplemental measuring techniques are needed to explore the effect of PDT on the integrity of microbial biofilms. In addition, whether PDT is equally effective when used on biofilms formed by other microbial species or complex microbial communities remains to be determined. Rates of bacterial dead reported in the literature are highly diverse as experimental conditions are too. Our data are higher than those reported by Soukos and Goodson [2] when they describe that photodynamic therapy killed approximately $63 \%$ of bacteria present in suspension, whereas in biofilms, photodynamic therapy had much less effect reaching $32 \%$ maximal killing. It should be noted that in this work, we have used higher energy fluence and power density. Moreover, it has been shown that PDT efficacy is strain dependent [24].

Acknowledgments The authors wish to thank the Centres Cientifics i Tecnològics (Universitat de Barcelona, Campus de Bellvitge, Barcelona, Spain) and particularly Dr. Benjamin Torrejón for their technical assistance in CLSM.

Conflict of interest The authors declare that they have no conflict of interest. Authors disclose all relationships or interests that could have direct or potential influence or impart bias on the work.

Ethical statement The manuscript has not been submitted to more than LIMS for simultaneous consideration. The material has not been published previously (partly or in full). This study is not split up into several parts to increase the quantity of submissions and submitted to various journals or to one journal over time. No data have been fabricated or manipulated (including images) to support our conclusions.

All authors agree to submit and they have explicitly signed an agreement document. Authors whose names appear on the submission have contributed sufficiently to the scientific work and therefore share collective responsibility and accountability for the results.

Open Access This article is distributed under the terms of the Creative Commons Attribution 4.0 International License (http:// creativecommons.org/licenses/by/4.0/), which permits unrestricted use, distribution, and reproduction in any medium, provided you give appropriate credit to the original author(s) and the source, provide a link to the Creative Commons license, and indicate if changes were made.

\section{References}

1. Donlan RM, Costerton JW (2002) Biofilms: survival mechanisms of clinically relevant microorganisms. Clin Microbiol Rev 15:167193

2. Soukos NS, Goodson JM (2000) Photodynamic therapy in the control of oral biofilms. Periodontol 55:143-166

3. Rosan B, Lamont RJ (2000) Dental plaque formation. Microbes Infect 2:1599-1607

4. Marsh PD (2005) Dental plaque: biological significance of a biofilm and community life-style. J Clin Periodontol 32(Suppl 6):7-15

5. Dötsch A, Eckweiler D, Schniederjans M et al (2012) The Pseudomonas aeruginosa transcriptome in planktonic cultures and static biofilms using RNA sequencing. PLoS One 7:e31092. doi:10.1371/journal.pone.0031092

6. Davies D (2003) Understanding biofilm resistance to antibacterial agents. Nat Rev Discov 2:114-122

7. Konopka K, Goslinski T (2007) Photodynamic therapy in dentistry. J Dent Res 86:694-707

8. Cheng X, Guan S, Lu H et al (2012) Evaluation of the bactericidal effect of Nd:YAG, Er:YAG, Er, Cr:YSGG laser radiation, and 
antimicrobial photodynamic therapy (aPDT) in experimentally infected root canals. Lasers Surg Med 44:824-831

9. Maisch T, Hackbarth S, Regensburger J et al (2011) Photodynamic inactivation of multi-resistant bacteria (PIB) - a new approach to treat superficial infections in the 21 st century. J Dtsch Dermatol Ges 9:360-366

10. Odor TM, Watson TF, Pitt Ford TR, McDonald F (1996) Pattern of transmission of laser light in teeth. Int Endod J 29:228-234

11. Gutknecht N, van Gogswaardt D, Conrads G et al (2000) Diode laser radiation and its bactericidal effect in root canal wall dentin. $\mathrm{J}$ Clin Laser Med Surg 18:57-60

12. Schoop U, Kluger W, Moritz A et al (2004) Bactericidal effect of different laser systems in the deep layers of dentin. Lasers Surg Med 35:111-116

13. Bahcall J, Howard P, Miserendino L, Walia H (1992) Preliminary investigation of the histological effects of laser endodontic treatment on the periradicular tissues in dogs. J Endod 18:47-51

14. Turkmen C, Gunday M, Karacorlu M, Basaran B (2000) Effect of $\mathrm{CO} 2, \mathrm{Nd}: \mathrm{YAG}$, and ArF excimer lasers on dentin morphology and pulp chamber temperature: an in vitro study. J Endod 26:644-648

15. Nunes MR, Mello I, Franco GC et al (2011) Effectiveness of photodynamic therapy against Enterococcus faecalis, with and without the use of an intracanal optical fiber: an in vitro study. Photomed Laser Surg 29:803-808

16. Lee MT, Bird PS, Walsh LJ (2004) Photo-activated disinfection of the root canal: a new role for lasers in endodontics. Aust Endod $\mathrm{J}$ 30:93-98

17. Wainwright M, Crossley KB (2004) Photosensitising agentscircumventing resistance and breaking down biofilms: a review. Int Biodeterior Biodegrad 53:119-126

18. Rios A, He J, Glickman GN et al (2011) Evaluation of photodynamic therapy using a light-emitting diode lamp against Enterococcus faecalis in extracted human teeth. J Endod 37:856-859

19. Vaziri S, Kangarlou A, Shahbazi R et al (2012) Comparison of the bactericidal efficacy of photodynamic therapy, $2.5 \%$ sodium hypochlorite, and $2 \%$ chlorhexidine against Enterococcous faecalis in root canals; an in vitro study. Dent Res J 9:613-618

20. Zand V, Milani AS, Amini M et al (2013) Antimicrobial efficacy of photodynamic therapy and sodium hypochlorite on monoculture biofilms of Enterococcus faecalis at different stages of development. Photomed Laser Surg 32:245-51

21. Garcez AS, Nunez SC, Hamblim MR et al (2010) Photodynamic therapy associated with conventional endodontic treatment in patients with antibiotic-resistant microflora: a preliminary report. J Endod 36:1463-1466

22. Muhammad OH, Chevalier M, Rocca JP, Brulat-Bouchard N, Medioni E (2014) Photodynamic therapy versus ultrasonic irrigation: interaction with endodontic microbial biofilm, an ex vivo study. Photodiagn Photodyn Ther 11:171-81

23. Yildirim C, Karaarslan ES, Ozsevik S, Zer Y, Sari T, Usumez A (2013) Antimicrobial efficiency of photodynamic therapy with different irradiation durations. Eur J Dent 7:469-73

24. Silva TC, Pereira AF, Buzalaf MA, Machado MA, Crielaard W, Deng DM (2014) Diverse outcomes of photodynamic antimicrobial chemotherapy on five Enterococcus faecalis strains. Photodiagn Photodyn Ther 11:283-9

25. Costerton JW, Stewart PS, Greenberg EP (1999) Bacterial biofilms: a common cause of persistent infections. Science 284:1318-1322

26. Dorobantu LS, Goss GG, Burrell RE (2012) Atomic force microscopy: a nanoscopic view of microbial cell surfaces. Micron 43: $1312-1322$

27. Gillis A, Dupres V, Delestrait G et al (2012) Nanoscale imaging of Bacillus thuringiensis flagella using atomic force microscopy. Nanoscale 4:1585-1591

28. Díaz C, Schilardi PL, Salvarezza RC, de Fernández Lorenzo Mele M (2011) Have flagella a preferred orientation during early stages of biofilm formation?: AFM study using patterned substrates. Colloids Surf B: Biointerfaces 82:536-542

29. Andre G, Deghorain M, Bron PA et al (2011) Fluorescence and atomic force microscopy imaging of wall teichoic acids in Lactobacillus plantarum. ACS Chem Biol 6:366-376

30. Francius G, Domenech O, Mingeot-Leclercq MP, Dufrêne YF (2008) Direct observation of Staphylococcus aureus cell wall digestion by lysostaphin. J Bacteriol 190:7904-7909

31. Muller DJ, Krieg M, Alsteens D, Dufrene YF (2009) New frontiers in atomic force microscopy: analyzing interactions from singlemolecules to cells. Curr Opin Biotechnol 20:4-13

32. Bolshakova AV, Kiselyova OI, Yaminsky IV (2004) Microbial surfaces investigated using atomic force microscopy. Biotechnol Prog 20:1615-1622

33. Núñez ME, Martin MO, Chan PH et al (2005) Atomic force microscopy of bacterial communities. Methods Enzymol 397:256-268

34. Silva Junior A, Teschke O (2005) Dynamics of the antimicrobial peptide PGLa action on Escherichia coli monitored by atomic force microscopy. World J Microbiol Biotechnol 21:1103-1110

35. Bolshakova AV, Kiselyova OI, Filonov AS et al (2001) Comparative studies of bacteria with an atomic force microscopy operating in different modes. Ultramicroscopy 86:121-128

36. Robichon D, Girard JC, Cenatiempo Y, Cavellier JF (1999) Atomic force microscopy imaging of dried or living bacteria. C R Acad Sci III 322:687-693

37. Núñez ME, Martin MO, Chan PH, Spain EM (2005) Predation, death, and survival in a biofilm: Bdellovibrio investigated by atomic force microscopy. Colloids Surf B: Biointerfaces 42:263-271

38. Jonas K, Tomenius H, Kader A et al (2007) Roles of curli, cellulose and BapA in Salmonella biofilm morphology studied by atomic force microscopy. BMC Microbiol 7:70

39. Rossetto G, Bergese P, Colombi P et al (2007) Atomic force microscopy evaluation of the effects of a novel antimicrobial multimeric peptide on Pseudomonas aeruginosa. Nanomedicine 3:198-207

40. Canetta E, Walker GM, Adya AK (2009) Nanoscopic morphological changes in yeast cell surfaces caused by oxidative stress: an atomic force microscopic study. J Microbiol Biotechnol 19:547-555

41. Sahu K, Bansal H, Mukherjee C (2009) Atomic force microscopic study on morphological alterations induced by photodynamic action of Toluidine Blue O in Staphylococcus aureus and Escherichia coli. J Photochem Photobiol Biol 96:9-16

42. Liu S, Ng AK, Xu R et al (2010) Antibacterial action of dispersed single-walled carbon nanotubes on Escherichia coli and Bacillus subtilis investigated by atomic force microscopy. Nanoscale 2: 2744-2750

43. Fernandes JC, Eaton P, Gomes AM et al (2009) Study of the antibacterial effects of chitosans on Bacillus cereus (and its spores) by atomic force microscopy imaging and nanoindentation. Ultramicroscopy 109:854-860

44. Deupree SM, Schoenfisch MH (2009) Morphological analysis of the antimicrobial action of nitric oxide on Gram-negative pathogens using atomic force microscopy. Acta Biomater 5:1405-1415

45. Botta SB, Ana PA, de Sa Teixeira F et al (2011) Relationship between surface topography and energy density distribution of $\mathrm{Er}, \mathrm{Cr}$ : YSGG beam on irradiated dentin: an atomic force microscopy study. Photomed Laser Surg 29:261-269

46. Bhatti M, MacRobert A, Meghji S et al (1998) A study of the uptake of toluidine blue $\mathrm{O}$ by Porphyromonas gingivalis and the mechanism of lethal photosensitization. Photochem Photobiol 68:370-376

47. de Melo MA, Rolim JP, Zanin IC et al (2013) Characterization of antimicrobial photodynamic therapy-treated Streptococci mutans: an atomic force microscopy study. Photomed Laser Surg 31:105-109

48. Garcez AS, Núñez SC, Azambuja N Jr et al (2013) Effects of photodynamic therapy on Gram-positive and Gram-negative bacterial biofilms by bioluminescence imaging and scanning electron microscopic analysis. Photomed Laser Surg 31:519-25 